\title{
Recent trends in life expectancy for people with type 1 diabetes in Sweden
}

\author{
Dennis Petrie $^{1}$ (D) - Tom W. C. Lung ${ }^{1,2} \cdot$ Aidin Rawshani $^{3}$ • Andrew J. Palmer ${ }^{4}$. \\ Ann-Marie Svensson ${ }^{3} \cdot$ Björn Eliasson $^{3} \cdot$ Philip Clarke $^{1}$
}

Received: 8 September 2015 / Accepted: 19 February 2016 / Published online: 5 April 2016

(C) Springer-Verlag Berlin Heidelberg 2016

\begin{abstract}
Aims/hypothesis People with type 1 diabetes have reduced life expectancy (LE) compared with the general population. Our aim is to quantify mortality changes from 2002 to 2011 in people with type 1 diabetes in Sweden.

Methods This study uses health records from the Swedish National Diabetes Register (NDR) linked with death records. Abridged period life tables for those with type 1 diabetes aged 20 years and older were derived for 2002-06 and 2007-11 using Chiang's method. Cox proportional hazard models were used to assess trends in overall and cause-specific mortality. Results There were 27,841 persons aged 20 years and older identified in the NDR as living with type 1 diabetes between 2002 and 2011, contributing 194,685 person-years of followup and 2,018 deaths. For men with type 1 diabetes, the remaining LE at age 20 increased significantly from 47.7 $(95 \%$ CI $46.6,48.9)$ in $2002-06$ to 49.7 years $(95 \%$ CI 48.9 , $50.6)$ in 2007-11. For women with type 1 diabetes there was
\end{abstract}

Electronic supplementary material The online version of this article (doi:10.1007/s00125-016-3914-7) contains peer-reviewed but unedited supplementary material, which is available to authorised users.

Dennis Petrie

dennis.petrie@unimelb.edu.au

1 Centre for Health Policy, Melbourne School of Population and Global Health, University of Melbourne, Carlton, Melbourne, VIC 3053, Australia

2 The George Institute for Global Health, University of Sydney, Sydney, NSW, Australia

3 Institute of Medicine, Sahlgrenska University Hospital, University of Gothenburg, Gothenburg, Sweden

4 The Menzies Institute for Medical Research, University of Tasmania, Hobart, TAS, Australia no significant change, with an LE at age 20 of 51.7 years $(95 \%$ CI $50.3,53.2)$ in $2002-06$ and 51.9 years $(95 \%$ CI 50.9, 52.9) in 2007-11. Cardiovascular mortality significantly reduced, with a per year HR of $0.947(95 \%$ CI $0.917,0.978)$ for men and $0.952(95 \%$ CI $0.916,0.989)$ for women.

Conclusions/interpretation From 2002-06 to 2007-11 the LE at age 20 of Swedes with type 1 diabetes increased by approximately 2 years for men but minimally for women. These recent gains have been driven by reduced cardiovascular mortality.

Keywords Life expectancy $\cdot$ Relative mortality $\cdot$ Type 1 diabetes

$\begin{array}{ll}\text { Abbreviations } \\ \text { eGFR } & \text { Estimated GFR } \\ \text { ESRD } & \text { End stage renal disease } \\ \text { LE } & \text { Life expectancy } \\ \text { NDR } & \text { Swedish National Diabetes Register } \\ \text { SMR } & \text { Standardised mortality ratio } \\ \text { UAE } & \text { Urinary albumin excretion rate }\end{array}$

\section{Introduction}

It has long been established that people with type 1 diabetes have higher mortality and reduced life expectancy (LE) compared with the general population $[1,2]$. Having accurate LE estimates allows us to identify gaps between populations in order to identify areas for potential improvement and quantify improvements in healthcare over time [3, 4]. LE estimates feed into life insurance premiums and allow insurance companies to quantify and manage risks $[5,6]$. The information 
can also be used by people with diabetes to make better planning decisions about matters such as retirement [7].

Previous studies have estimated the impact of type 1 diabetes on mortality and LE and compared these with variables in the general population [1, 8-14]. There is some evidence that survival of people with type 1 diabetes relative to the general population has improved since the 1940s [6] and has continued to improve in recent years [15]. One Australian study comparing people with type 1 diabetes with the general population estimated that the standardised mortality ratio (SMR) decreased from 4.20 in 1997 to 3.08 in 2010 [16]. Similarly, LE has improved over time [5]. However, the gap still remains. A recent study in Scotland found that from 20 years of age, men and women with type 1 diabetes lose about 11 and 13 years of LE, respectively, compared with the general population [17]. Renal and cardiovascular disease (CVD) have been identified as comorbidities that contribute to excess mortality, especially after the first 10 years from type 1 diabetes onset [12,14, 18-21]. There is some evidence to suggest that improvements in diabetes care have delayed the progression of renal disease [14].

The current paper addresses whether mortality and LE have changed for men and women with type 1 diabetes in Sweden from 2002 to 2011, and examine how these changes compare with changes in the general population. In addition, we also explore whether any secular trends in mortality over this period can be explained by improvements in risk factors associated with diabetes-related complications and further investigate mortality by cause to examine where recent gains have been made.

\section{Methods}

This study uses Swedish data for those with type 1 diabetes and compares their mortality with that of the general population in Sweden.

Diabetes population The Swedish National Diabetes Register (NDR) stores individuals' clinical details from registered centres across all of Sweden [22]. It records demographic data, diabetes duration and treatment modalities, as well as various risk factors measured at least annually and diabetes complications from actual patient visits in primary healthcare or hospital outpatient clinics for all diabetes patients [23, 24].

This study is based on four sources of data: (1) risk factor data from the Swedish NDR (1 January 1987 to 31 December 2010); (2) hospital records of inpatient episodes from the National Inpatient Register (1 January 1987 to 31 December 2011) [25]; (3) death records (1 January 2002 to 31 December 2011); and (4) prescription data records (1 July 2005 to 31 December 2011) [26]. The data were confidentially linked at the patient level by the NDR. The Central Ethical Review Board at the University of Gothenburg approved the study.

Our sample included patients with type 1 diabetes who visited a clinic after 2002 and were registered in the NDR. The number of clinics that placed their patients' data in the NDR rapidly increased from 2002 and currently there is nearly $90 \%$ coverage of the population with type 1 diabetes [27]. To ensure those with type 2 diabetes and emigrants are excluded, we defined a person as having type 1 diabetes if diagnosed under the age of 30 years, reported as being treated with insulin only at some clinic visit, and when alive, having had at least one prescription for insulin filled per year between 2006 and 2010 (full calendar years where prescription data were available) and without a prescription filled for metformin at any point between July 2005 and December 2010. A flow diagram with the numbers excluded at each criterion is given in electronic supplementary material (ESM) Fig. 1. Patients entered as being at risk of death from the date of their first NDR clinic visit after 1 January 2002 until they died or were censored at the final study date (31 December 2011).

All $\mathrm{HbA}_{1 \mathrm{c}}$ values were converted to National Glycohemoglobin Standardization Program (NGSP) standard levels [28]. Microalbuminuria was defined as two positive tests out of three samples taken within a year, with albumin/ creatinine ratio $3-30 \mathrm{mg} / \mathrm{mmol}$ or urinary albumin excretion rate (UAE) of $20-200 \mu \mathrm{g} / \mathrm{min}$ or $20-300 \mathrm{mg} / 1$ and macroalbuminuria as albumin/creatinine ratio $>30 \mathrm{mg} / \mathrm{mmol}$ or UAE $>200 \mu \mathrm{g} / \mathrm{min}$ or $>300 \mathrm{mg} / \mathrm{l}$. Estimated GFR (eGFR) was calculated using the Chronic Kidney Disease Epidemiology Collaboration (CKD-EPI) formula [29]. Descriptive statistics of risk factors and event history of those at their first NDR visit in 2002 and alive at the end of 2011 are reported by sex. Mean values adjusted using linear regression for current age and age at diagnosis are also reported. Given that the same individuals may have been alive in 2002 and at the end of 2011, we bootstrapped the sample at the individual level with 2,000 replications to test for significant differences in the means of the risk factors between 2002 and 2011.

Classification of deaths For those with type 1 diabetes, deaths were classified by cause of death into deaths related to CVD, renal disease and other causes. Where a general diabetes-related ICD code was given as the primary cause of death, it was re-classified as CVD or renal death if a CVD or renal ICD code was found in the secondary causes $[8,30]$. The specific ICD codes used can be found in the ESM Methods.

General population Annual mortality rates and LE information by sex for the general Swedish population were obtained from Eurostat [31]. These were then used to estimate for each NDR individual the expected mortality by year if they had been exposed to the same mortality as the general population. Cause-specific mortality rates for the general population were 
also used. However, 2010 cause-specific mortality rates from Eurostat were used for 2011 as the 2011 rates were not available.

Statistical analysis We defined LE for people with type 1 diabetes as the expected remaining years to be lived for someone aged 20 with type 1 diabetes if they were exposed to the same mortality as the current mortality faced by older individuals alive and diagnosed with type 1 diabetes (a period life table assumption). To do this we used abridged period life tables by sex for those with type 1 diabetes in Sweden aged 20 years and older, derived for 2002-06 and 2007-11 using Chiang's method for 5-year age intervals (plus an open-ended interval for 80 years and older) [32]. The mortality rates for each age-sex-time group were calculated based on the number of deaths observed for each age-sex-time group in the period divided by the total time at risk observed for each age-sex-time group. As the NDR does not have paediatric data, we considered LE from 20 years.

LE for people with type 1 diabetes was also compared with the LE of the general Swedish population. This allowed us to put into context changes observed in the population with type 1 diabetes vs the changes seen over this period in the general Swedish population and to quantify LE gaps at different ages. SMRs compared with rates in the general population were estimated using weights based on the population structure of individuals with type 1 diabetes in the NDR in 2010. In addition, to quantify the differences in type 1 diabetes LE across countries, the LE results were compared with a recent Scottish study (2008-10) [17]. Bootstrap techniques were used to derive the $95 \%$ CI for LE and SMR, with 1,000 samples generated and sampling conducted at the individual level to reflect the sampling design. When no deaths were recorded in the population with type 1 diabetes the general population mortality rate for that period was used instead [17].

A Cox proportional hazards model was then estimated for survival where, first, only a linear trend for the year and the age at diagnosis were included as explanatory factors to see whether there was a systematic improvement in mortality rates over time. Second, we also included a number of other timevarying risk factors to explore the extent to which any trends observed could be explained by variations in these risk factors over time. Risk factor values were carried forward and updated when available at subsequent clinic visits, including values for micro- and macroalbuminuria. We did not directly control for a history of diabetes-related complications or events as it is expected that changes in the risk factors would act through reducing the occurrence of these complications, and death would naturally be a consequence of many of these complications. Finally, the trend in relative mortality compared with the general population was considered by including the natural $\log$ of the general population mortality rate for each sex as an offset variable in the Cox proportional hazards model where its coefficient was restricted to one. This allowed investigation of relative mortality changes over time [33, 34].

Several sensitivity analyses were conducted. First, we examined year-to-year trends by including a dummy variable for each year. Second, we included dummy variables for the year of NDR entry as additional explanatory variables to explore whether results were influenced by possible selection bias due to those entering the NDR sample earlier being systematically sicker or healthier than those who entered later. Third, we considered an expanded sample that included all those diagnosed under the age of 30 (including those on metformin or with insulin prescriptions missing). Fourth, we used multiple imputation with chained regressions (five imputations) to adjust for missing risk factor data [35].

To further investigate potential trends in specific causes of death, we employed a competing risk Cox proportional hazards model where deaths were split by the major causes of excess mortality in the population with type 1 diabetes: CVD-related, renal-disease-related and other causes. We explored whether a linear time trend was observed for each cause of death while controlling for age at diabetes diagnosis, as well as trends in relative mortality, by offsetting the model with the natural $\log$ of the general population cause-specific mortality rate by age group. All analyses were undertaken using STATA (StataCorp 2011. Stata Statistical Software: release 12.1. College Station, TX, USA).

\section{Results}

There were 27,841 people identified in the NDR as living with type 1 diabetes in Sweden and at risk of death at some point between 2002 and 2011 inclusive, contributing 194,685 person-years of follow-up. Overall, 2,018 deaths were observed. The ages ranged from 17.0 to 97.7 years.

Table 1 provides descriptive statistics, by sex, of risk factors and event history of those in the NDR at the first NDR visit in 2002 and alive at the end of 2011. The numbers alive in the registry increased during this period as more clinics registered their data in the NDR (see ESM Results for individuals added each year). The average level of some important risk factors changed significantly over this period: $17 \%$ more men and $13 \%$ more women reported being on lipid-lowering medication and also had lower HDL-cholesterol, LDL-cholesterol and triacylglycerols; $\mathrm{HbA}_{1 \mathrm{c}}$ and $\mathrm{BMI}$ slightly increased while systolic $\mathrm{BP}$ and the proportion of smokers decreased. Renal function improved, with 5-6\% fewer people with microalbuminuria and 3-4\% fewer people with macroalbuminuria, while eGFR increased. The proportion of people alive with a history of diabetes-related events increased significantly for most event types for both men and women. Similar risk factor differences were seen even after adjusting for differences in age and age at diagnosis between the 2 years. 


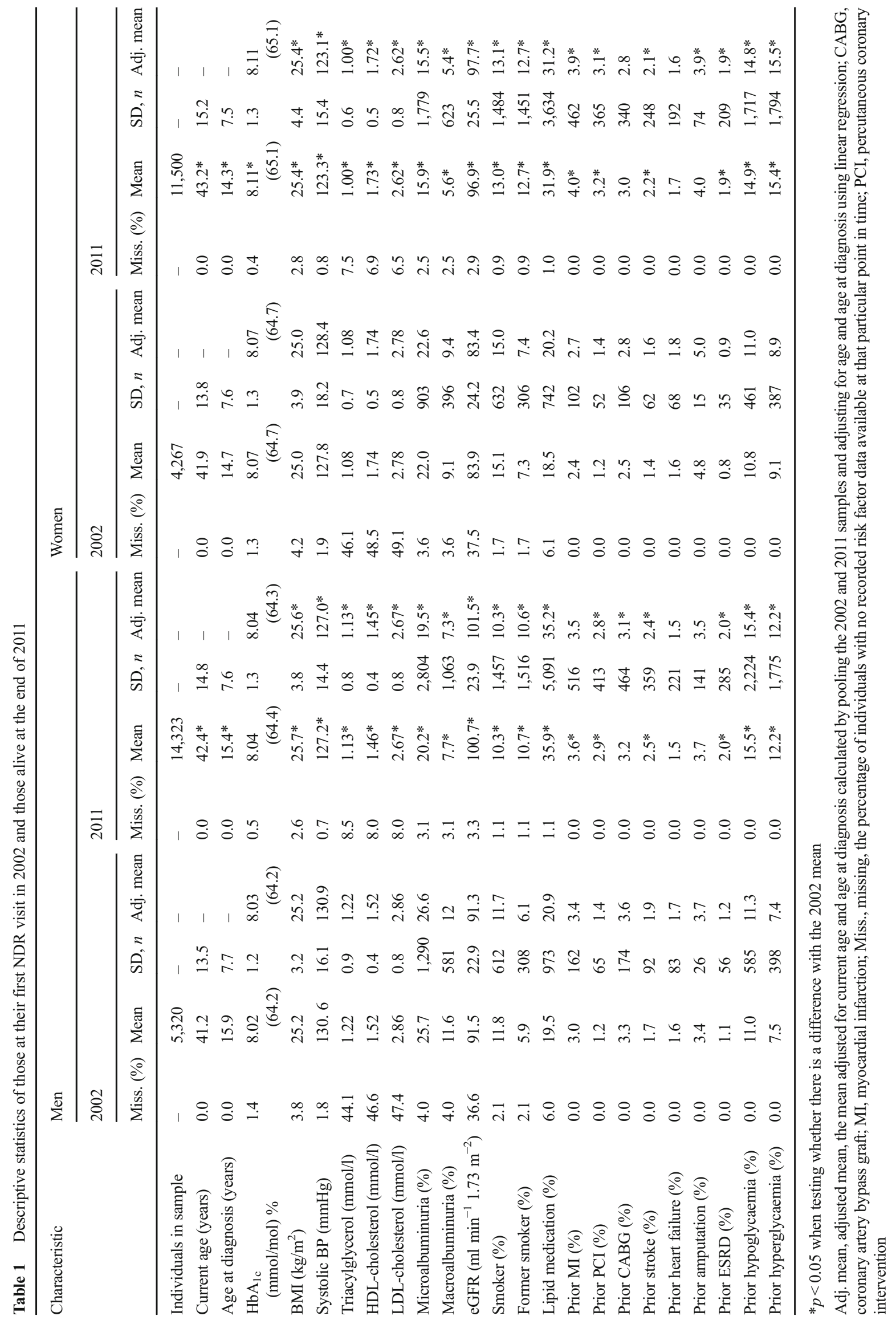


LE trends for people with type 1 diabetes in Sweden Figure 1a, b illustrates cumulative mortality for the period 2002-06 and 2007-11 for those with type 1 diabetes and the general population for men and women, respectively. These graphs show a significant improvement in survival for men and little change for women over the two time periods. However, a large gap persists between the men and women with type 1 diabetes and the general populations.

For those with type 1 diabetes, the estimated remaining LE at age 20 increased from 47.7 (95\% CI 46.6, 48.9) and 51.7 years $(95 \%$ CI $50.3,53.2)$ in $2002-06$ to 49.8 (95\% CI $49.0,50.7)$ and 51.9 years $(95 \%$ CI $50.9,52.9)$ in $2007-11$ for men and women, respectively. Male LE significantly increased by 2.1 years $(95 \%$ CI $0.7,3.4)$, but female LE was unchanged $(95 \% \mathrm{CI}-1.6,1.9)$. Figure $2 \mathrm{a}, \mathrm{b}$ compares the expected remaining LE at each age for men and women with type 1 diabetes with that of the general population.

LE gaps and SMRs compared with the general population for people with type $\mathbf{1}$ diabetes in Sweden Overall, the Swedish LE gap at age 20 between those with type 1 diabetes and the general population changed from 11.4 (95\% CI 10.2, $12.4)$ to 10.2 years $(95 \%$ CI $9.4,11.1)$ for men and from 11.6
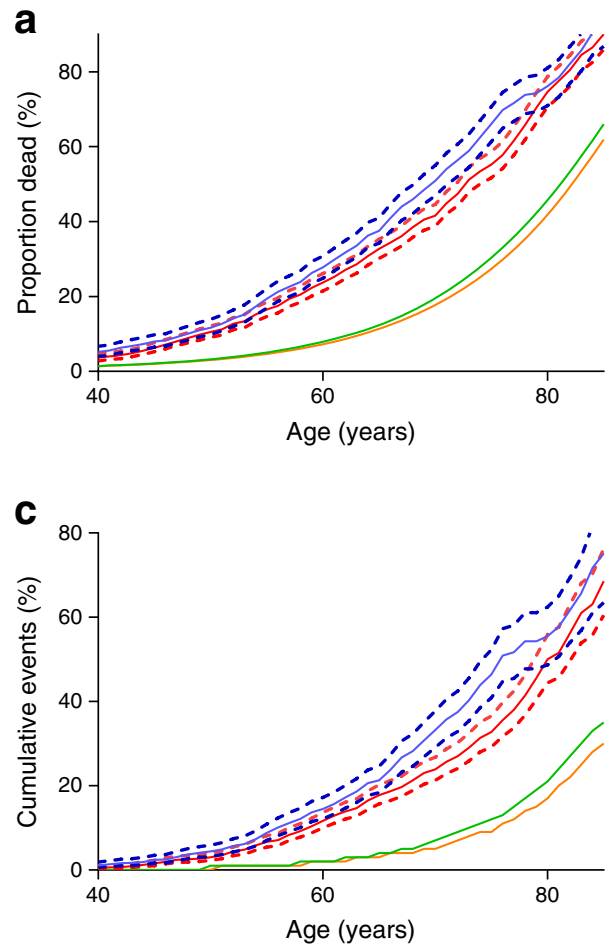

Fig. 1 All-cause and CVD cumulative mortality by age and sex of those with type 1 diabetes vs the general population from 2002-06 to 2007-11. (a) Men, all-cause mortality; (b) women, all-cause mortality; (c) men, CVD mortality events; and (d) women, CVD mortality events. Blue, NDR population with type 1 diabetes 2002-06; red, NDR population with type 1 diabetes 2007-11; green, general population 2002-06; orange, general population 2007-11. Dotted lines represent 95\% CI for cumulative mortality. Mortality for the general population is the expected
(95\% CI $10.1,13.0)$ to 12.0 years $(95 \%$ CI $11.0,13.0)$ for women from 2002-06 to 2007-11. Neither of these changes was significant. The 2002-06 SMR for men and women with type 1 diabetes compared with the general population was 3.03 (95\% CI 2.76, 3.31) and 3.38 (95\% CI 2.98, 3.82), respectively. For 2007-11, the SMR was significantly lower at $2.56(95 \%$ CI $2.37,2.75)$ for men, while there was no significant change for women (3.74 [95\% CI 3.42, 4.06]). Similar results hold for the extended sample including all those diagnosed $<30$ years of age (see ESM Results).

Testing for linear trends in mortality with survival models The Cox proportional hazards model with only a linear trend and age at diagnosis included shows men with type 1 diabetes experienced a significant negative trend in terms of mortality with HR 0.971 (95\% CI 0.950, 0.992) implying an approximate 3\% reduction in mortality per year from 2002 till 2011 (Table 2). The same trend was absent for women, being both very small and not significant (0.996 [95\% CI 0.970, 1.023]) (see ESM Fig. 2 for non-linear trend results). The second model in Table 2 estimated the HR for the trend for mortality relative to the general population to be 0.993 (95\% CI 0.972 , $1.016)$ and 1.017 (95\% CI 0.990, 1.044) for men and women,

b

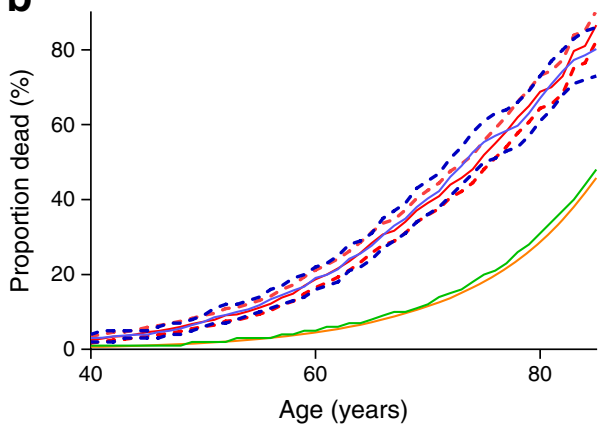

d

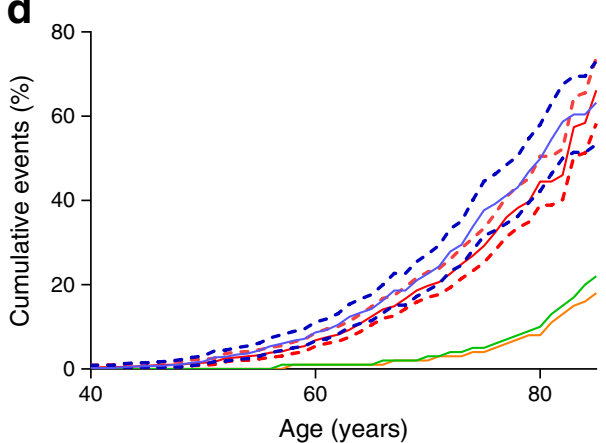

cumulative mortality if those with type 1 diabetes had the same annual mortality rate as the general population. The logrank test for the two time periods found significant differences for all-cause $(p=0.001)$ and CVD $(p<0.001)$ mortality for men but no significant evidence for all-cause $(p=0.968)$ or CVD mortality ( $p=0.063$ ) for women, though a test for a trend in the mortality function for women based on the year found a significant trend for CVD mortality $(p=0.023)$ 

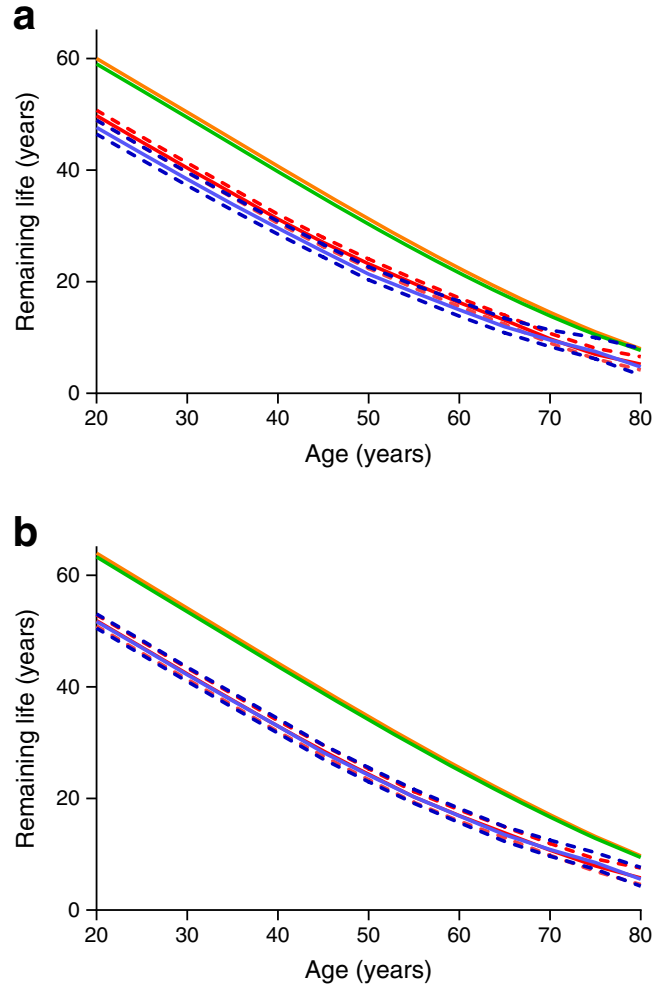

Fig. 2 Remaining LE for those with type 1 diabetes compared with the general population. (a) Men; and (b) women. Blue, NDR population with type 1 diabetes 2002-06; red, NDR population with type 1 diabetes 2007-11; green, general population 2002-06; orange, general population 2007-11. Dotted lines represent 95\% CI around the expected remaining $\mathrm{LE}$ at each age for the NDR population

respectively. These are insignificant and close to 1 , suggesting a consistent trend in mortality for both the populations with type 1 diabetes and the general Swedish population. The third model in Table 2 illustrates that after controlling for changes in a number of clinical risk factors over time, the male trend in mortality was no longer significant $(95 \%$ CI $0.979,1.032)$. Significant risk factors for both male and female mortality included $\mathrm{HbA}_{1 \mathrm{c}}$, $\mathrm{BMI}$, $\mathrm{BP}$, triacylglycerol, microalbuminuria, macroalbuminuria, eGFR and smoking status. High BMI and systolic BP are, however, significant predictors of lower mortality after controlling for other factors. The results do not change when possible selection bias is accounted for (see ESM Results) and when multiple imputation is conducted for missing risk factor values (see ESM Results).

\section{Type 1 diabetes mortality trends by cause of death} Figure $1 \mathrm{c}, \mathrm{d}$ shows the cumulative CVD mortality events for men and women with type 1 diabetes and the general population. There were improvements for both men and women with type 1 diabetes over the two periods, but only the improvements in men were significant with logrank testing. Large differences were observed for CVD mortality events for those with type 1 diabetes vs the general population. However, renal and other causes showed little change over time (see ESM Fig. 3).

Table 3 shows the linear trends in mortality, by sex, using Cox competing mortality models for CVD, renal disease and other mortality. Of the 1,183 total deaths in men, 50\% (588) were related to CVD, $6 \%$ (66) to renal disease and $45 \%$ (529) to other causes. For the 833 deaths in women, $48 \%$ (404), $6 \%$ (49) and $46 \%$ (380) were classified as related to CVD, renal disease and other causes, respectively. The Cox competing risk models for CVD mortality showed a significant reduction in mortality over time, with a per year HR of 0.947 (95\% CI $0.917,0.978)$ for men and $0.952(95 \%$ CI $0.916,0.989)$ for women. This suggests for both sexes an approximate 5\% relative reduction in CVD mortality rates per year. As expected, an earlier age at diagnosis significantly increased cardiovascular mortality for both men and women. There was no significant relationship found between age at diabetes diagnosis and mortality for renal disease or other causes, though given the small number of deaths related to renal disease there was little power to detect such a relationship. A significant positive trend was found for other-cause mortality for women with type 1 diabetes relative to the general population.

\section{Discussion}

The estimated mortality rates of those with type 1 diabetes at different ages were comparable but slightly lower than those found in other studies [15]. From 2002-06 to 2007-11 the LE of those with type 1 diabetes in Sweden increased for men by about 2 years, with no comparable evidence of any increase for women. However, this has not significantly closed the LE gap with the general population for men in absolute terms as a similar improvement was seen in the general population. Given that the mortality trend for men disappeared when we controlled for risk factors, the secular trend for men could potentially be explained by changes in risk factors. When mortality was broken down into CVD, renal disease and other causes, we found that mortality relating to CVD significantly decreased from 2002-10 for both men and women. The improvement in CVD mortality coincided with the large increase in the proportion of the population with type 1 diabetes who reported being on lipid-lowering medication and the associated decrease in cholesterol over this period. However, similar relative improvements in the general Swedish population for CVD were also observed, which suggests a similar uptake in lipid-lowering medication in the general population [36]. Also, reductions in smoking rates for the population with type 1 diabetes were also likely to have contributed to the lower CVD mortality. For Swedes with type 1 diabetes at the age of 20, the LE gap vs the general population was about 10-11 and 11-12 years for men and women, respectively. Interestingly, the secular trend in mortality was no longer significant for men when we controlled for metabolic risk 
Table 2 Cox proportional hazards models for mortality and relative mortality for those with type 1 diabetes

\begin{tabular}{|c|c|c|c|c|c|c|}
\hline \multirow[t]{2}{*}{ Characteristic } & \multicolumn{3}{|l|}{ Men } & \multicolumn{3}{|l|}{ Women } \\
\hline & HR & $95 \% \mathrm{CI}$ & $p$ value & HR & $95 \% \mathrm{CI}$ & $p$ value \\
\hline \multicolumn{7}{|l|}{ Trend and age at diagnosis only } \\
\hline Year & $0.971^{*}$ & $(0.950,0.992)$ & 0.009 & 0.996 & $(0.970,1.023)$ & 0.785 \\
\hline Age at diabetes diagnosis & $0.985^{*}$ & $(0.977,0.992)$ & $<0.001$ & $0.980 *$ & $(0.971,0.988)$ & $<0.001$ \\
\hline \multicolumn{7}{|c|}{ Relative mortality against the general population } \\
\hline Year & 0.993 & $(0.972,1.016)$ & 0.551 & 1.017 & $(0.990,1.044)$ & 0.231 \\
\hline Age at diabetes diagnosis & $0.985^{*}$ & $(0.977,0.992)$ & $<0.001$ & $0.979 *$ & $(0.971,0.988)$ & $<0.001$ \\
\hline Number of deaths & & 1,183 & & & 833 & \\
\hline Individuals & & 15,508 & & & 12,333 & \\
\hline Person-years at risk & & 107,740 & & & 86,945 & \\
\hline \multicolumn{7}{|c|}{ Model accounting for risk factor changes } \\
\hline Year & 1.005 & $(0.979,1.032)$ & 0.699 & 1.017 & $(0.985,1.051)$ & 0.297 \\
\hline Age at diabetes diagnosis & 0.994 & $(0.986,1.003)$ & 0.190 & 0.994 & $(0.983,1.005)$ & 0.266 \\
\hline $\log _{e}\left(\mathrm{HbA}_{1 \mathrm{c}}, \%\right)$ & $2.641 *$ & $(1.659,4.206)$ & $<0.001$ & $2.558^{*}$ & $(1.492,4.386)$ & 0.001 \\
\hline BMI & $0.968 *$ & $(0.950,0.986)$ & 0.001 & $0.971 *$ & $(0.954,0.989)$ & 0.002 \\
\hline Systolic BP & $0.992 *$ & $(0.988,0.996)$ & $<0.001$ & $0.993 *$ & $(0.988,0.997)$ & 0.001 \\
\hline Triacylglycerol & $1.256^{*}$ & $(1.169,1.351)$ & $<0.001$ & $1.281^{*}$ & $(1.176,1.395)$ & $<0.001$ \\
\hline HDL-cholesterol & 1.121 & $(0.967,1.301)$ & 0.131 & $0.754^{*}$ & $(0.636,0.895)$ & 0.001 \\
\hline LDL-cholesterol & 1.060 & $(0.979,1.148)$ & 0.149 & 0.988 & $(0.902,1.082)$ & 0.788 \\
\hline Microalbuminuria $^{\mathrm{a}}$ & $1.691^{*}$ & $(1.419,2.015)$ & $<0.001$ & $1.714 *$ & $(1.392,2.111)$ & $<0.001$ \\
\hline Macroalbuminuria $^{\mathrm{a}}$ & $1.532 *$ & $(1.259,1.864)$ & $<0.001$ & 1.263 & $(0.979,1.630)$ & 0.073 \\
\hline $\log _{\mathrm{e}}(\mathrm{eGFR})$ & $0.481 *$ & $(0.427,0.543)$ & $<0.001$ & $0.437^{*}$ & $(0.380,0.502)$ & $<0.001$ \\
\hline Smoker & $1.970^{*}$ & $(1.644,2.361)$ & $<0.001$ & $1.675^{*}$ & $(1.336,2.100)$ & $<0.001$ \\
\hline Former smoker & $1.244 *$ & $(1.025,1.510)$ & 0.027 & 1.240 & $(0.983,1.565)$ & 0.069 \\
\hline Number of deaths & & 912 & & & 632 & \\
\hline Individuals & & 13,342 & & & 10,743 & \\
\hline Person-years at risk & & 85,181 & & & 69,543 & \\
\hline
\end{tabular}

${ }^{\mathrm{a}}$ The albuminuria results are relative to normoalbuminuria

Cox regressions were fitted separately by sex and included age at diagnosis because these factors are considered external factors which influence mortality risk. The missing risk factor data meant that the model that accounts for risk factor changes has fewer person-years at risk and deaths; results using multiple imputation are reported in ESM Results. The offset models have the natural log of the general population mortality rate for each sex included in the Cox proportional hazards model with the coefficient restricted to one. All models (apart from the male model accounting for changes in risk factors) did not find enough evidence at the $5 \%$ level of significance to reject the assumption of proportional hazards. For the male model, which accounts for risk factor changes, there is evidence to suggest a change in the HR over age for both HDL-cholesterol and systolic BP. However, accounting for this does not impact on the implied trend

${ }^{*} p<0.05$ factors, many of which have a significant impact on mortality (e.g. the association between triacylglycerol level and mortality for both men and women) [37]. The seemingly counterintuitive results for BMI may be because a high BMI is a marker for good historic glycaemic control - in the DCCT study the intensivetreatment group had significantly higher BMI [38] — or because the positive effects of greater lean mass in overweight and obese older people counterbalance the negative effects of greater fat mass on mortality [39]. In addition, low systolic BP may be a marker for underlying poor health rather than a cause of mortality, particularly in people with heart failure [40].
The Swedish LE results for 2007-11 can be compared with evidence from Scottish people with type 1 diabetes (2008-10), where the remaining LE at age 20 for men was estimated to be 46.2 years $(95 \%$ CI $45.3,47.3)$ and for women 48.1 years $(95 \%$ CI 46.9, 49.3) [17]. Thus, 20 year olds with type 1 diabetes in Sweden have, on average, an LE 3.5 (95\% CI 2.2, 4.8) and 3.8 years $(95 \%$ CI $2.2,5.2)$ longer than their Scottish counterparts for men and women, respectively. The Swedish type 1 diabetes LE gaps with the general population at age 20 are smaller than the Scottish gaps by $0.8(95 \% \mathrm{CI}-0.5,2.2)$ and $0.9(95 \% \mathrm{CI}$ $-0.6,2.4$ ) years for men and women, respectively, though these 
Table 3 Trends for CVD, ESRD and other mortality by sex from Cox competing hazards models

\begin{tabular}{|c|c|c|c|c|c|c|}
\hline \multirow[t]{3}{*}{ Result } & \multicolumn{6}{|c|}{ Mortality HR $(95 \% \mathrm{CI})[p$ value $]$} \\
\hline & \multicolumn{3}{|l|}{ Men } & \multicolumn{3}{|l|}{ Women } \\
\hline & $\begin{array}{l}\text { CVD } \\
>30 \text { years }\end{array}$ & $\begin{array}{l}\text { ESRD } \\
>50 \text { years }\end{array}$ & $\begin{array}{l}\text { Other } \\
\text { All years }\end{array}$ & $\begin{array}{l}\text { CVD } \\
>30 \text { years }\end{array}$ & $\begin{array}{l}\text { ESRD } \\
>50 \text { years }\end{array}$ & $\begin{array}{l}\text { Other } \\
\text { All years }\end{array}$ \\
\hline Annual trend & $\begin{array}{l}0.947 * \\
(0.917,0.978) \\
{[0.001]}\end{array}$ & $\begin{array}{l}1.044 \\
(0.944,1.153) \\
{[0.404]}\end{array}$ & $\begin{array}{l}1.006 \\
(0.985,1.008) \\
{[0.706]}\end{array}$ & $\begin{array}{l}0.952 * \\
(0.916,0.989) \\
{[0.012]}\end{array}$ & $\begin{array}{l}1.071 \\
(0.948,1.210) \\
{[0.140]}\end{array}$ & $\begin{array}{l}1.038 \\
(0.999,1.078) \\
{[0.054]}\end{array}$ \\
\hline Age at diabetes diagnosis & $\begin{array}{l}0.983 * \\
(0.972,0.993) \\
{[0.001]}\end{array}$ & $\begin{array}{l}0.987 \\
(0.951,1.025) \\
{[0.495]}\end{array}$ & $\begin{array}{l}0.996 \\
(0.985,1.039) \\
{[0.507]}\end{array}$ & $\begin{array}{l}0.976^{*} \\
(0.963,0.989) \\
{[<0.001]}\end{array}$ & $\begin{array}{l}0.965 \\
(0.925,1.007) \\
{[0.101]}\end{array}$ & $\begin{array}{l}0.995 \\
(0.982,1.009) \\
{[0.496]}\end{array}$ \\
\hline \multicolumn{7}{|c|}{ Relative mortality with the general population, offset with general population cause-specific mortality } \\
\hline Annual trend & $\begin{array}{l}0.985 \\
(0.954,1.017) \\
{[0.363]}\end{array}$ & $\begin{array}{l}1.050 \\
(0.949,1.161) \\
{[0.346]}\end{array}$ & $\begin{array}{l}1.016 \\
(0.984,1.050) \\
{[0.321]}\end{array}$ & $\begin{array}{l}0.989 \\
(0.953,1.027) \\
{[0.561]}\end{array}$ & $\begin{array}{l}1.100 \\
(0.970,1.248) \\
{[0.138]}\end{array}$ & $\begin{array}{l}1.052 * \\
(1.013,1.093) \\
{[0.008]}\end{array}$ \\
\hline Age at diabetes diagnosis & $\begin{array}{l}0.981 * \\
(0.970,0.992) \\
{[0.001]}\end{array}$ & $\begin{array}{l}0.985 \\
(0.948,1.023) \\
{[0.431]}\end{array}$ & $\begin{array}{l}0.995 \\
(0.983,1.006) \\
{[0.347]}\end{array}$ & $\begin{array}{l}0.973 * \\
(0.961,0.986) \\
{[<0.001]}\end{array}$ & $\begin{array}{l}0.962 \\
(0.921,1.004) \\
{[0.073]}\end{array}$ & $\begin{array}{l}0.994 \\
(0.980,1.007) \\
{[0.364]}\end{array}$ \\
\hline Number of deaths & 587 & 53 & 529 & 404 & 39 & 380 \\
\hline Person-years at risk & 82,187 & 70,489 & 107,562 & 67,194 & 58,475 & 86,823 \\
\hline
\end{tabular}

For CVD and renal mortality there were very few events under the ages of 30 and 50 years, respectively. In some years the general population mortality rates in these younger ages were estimated to be zero, which makes it difficult to consider differences in mortality from a relative perspective. Therefore, only mortality above age 30 and 50 years was considered for CVD and renal causes, respectively, while all ages were considered for the other-cause mortality. General population disease-specific mortality rates were only available up until the end of 2010 and therefore 2010 rates were used for 2011 $* p<0.05$

are not significant [17]. The SMRs estimated in this study are of a similar magnitude to those found in a cohort covering a similar time span in Denmark [15], but were significantly lower than the SMRs found for men (3.8) and women (5.8) in a recent metaanalysis [41]. The ratio of female to male SMRs was lower in Sweden for the period 2002-06 (1.12), but higher for the period 2007-11 (1.46) than the ratio in a recent meta-analysis (1.37) [41]. However, care needs to be taken when making conclusions by comparing SMRs across populations with differences in underlying mortality risk because a larger relative difference in mortality may still be a smaller difference in absolute terms $[42,43]$. This also applies to the current paper where gaps in LE are reported in absolute terms while the trends in the Cox regressions examine mortality differences in relative terms.

Compared with previous studies that have estimated LE in people with type 1 diabetes [5, 17], the strengths of this study are the large representative sample, the long length of followup, measurement of clinical risk factors and completeness of data. This is attributable to the NDR data, a large register that has been linked to hospital, prescription and death data. The NDR includes the vast majority of the Swedish type 1 diabetes population; $91 \%$ of $18-34$ year olds identified with type 1 diabetes from a 2009 prescribing registry data could be matched to those in the NDR [44]. This makes the consistent estimation of life tables for this population possible. However, participation in the NDR is not compulsory and our analysis requires patients to make at least one clinic visit in or after 2002; hence our analysis may have excluded a small proportion of the older and sicker patients in the earlier years. The NDR tracks patients using their personal identification number. However, for patients who emigrate it is not possible to know whether or when they died, or information that would allow them to be censored. Those alive and without at least one insulin prescription filled per year after 2005 were excluded from the analysis, and this should have excluded all those with type 1 diabetes who emigrated. Given the short-term nature of the data available, the LE estimates are from period life tables rather than cohort life tables. This means that recent improvements in care that take time to translate into reduced mortality may not show up in such an analysis. In addition, there may be misclassified causes of death [45], with renaldisease-related deaths misclassified as CVD or vice versa [13]. The Swedish renal mortality rates reported here are lower than those previously seen in a younger Japanese and US cohort where an expert committee based the cause of death classification on information from the attending physician or death certificates [14, 46-48]. However, the rates of end stage renal disease (ESRD) for those with type 1 diabetes in Sweden have previously been found to be low [49].

There is still some way to go in terms of improvement in care for those with type 1 diabetes in order to close the gap with the general population. A significant proportion have elevated 
$\mathrm{HbA}_{1 \mathrm{c}}$ levels and a recent paper based on the Swedish NDR highlighted the stark differences in mortality for those with well-controlled vs poorly controlled $\mathrm{HbA}_{1 \mathrm{c}}$ [50]. In addition, with $10 \%$ of men and $13 \%$ of women still reported as current smokers in 2011, additional smoking cessation programmes could generate further improvements. While there have been large increases in the use of lipid-lowering medication, further expansion could generate additional gains given this population's high underlying CVD risk. Future research might also provide individual specific LE estimates based on an individual's characteristics in terms of their age at diagnosis, and risk factor and comorbidity profiles. This would provide useful information for an individual and allow them to better grasp the likely benefits of improving their overall risk.

Funding The Swedish Association of Local Authorities and Regions funds the NDR. The study was supported in part by a National Health and Medical Research Council (NHMRC) Project Grant (1028335). This research was supported under the Australian Research Council's Discovery Early Career Awards funding scheme (Project DE150100309). The views expressed herein are those of the authors and are not necessarily those of the Australian Research Council.

Duality of interest The authors declare that there is no duality of interest associated with this manuscript.

Contribution statement DP, AP, BE, A-MS and PC contributed to the conception and design of the study; DP, TL, AR, AP, BE, AS and PC were involved in the data collection, analysis and interpretation; and DP, TL, AP and PC were involved in drafting the manuscript. All authors reviewed/edited the manuscript and approved the final version. DP is the guarantor of this work.

\section{References}

1. Soedamah-Muthu SS, Fuller JH, Mulnier HE et al (2006) All-cause mortality rates in patients with type 1 diabetes mellitus compared with a non-diabetic population from the UK general practice research database, 1992-1999. Diabetologia 49:660-666

2. Goodkin G (1975) Mortality factors in diabetes: a 20 year mortality study. J Occup Environ Med 17:716-721

3. Petrie D, Tang KK (2014) Relative health performance in BRICS over the past 20 years: the winners and losers. Bull World Health Organ 92:396-404

4. Leal J, Gray AM, Clarke PM (2009) Development of lifeexpectancy tables for people with type 2 diabetes. Eur Heart J 30: 834-839

5. Miller RG, Secrest AM, Sharma RK et al (2012) Improvements in the life expectancy of type 1 diabetes the Pittsburgh Epidemiology of Diabetes Complications Study Cohort. Diabetes 61:2987-2992

6. Borch-Johnsen K (1999) Improving prognosis of type 1 diabetes. Mortality, accidents, and impact on insurance. Diabetes Care 22: B1-B3

7. Van Solinge H, Henkens K (2010) Living longer, working longer? The impact of subjective life expectancy on retirement intentions and behaviour. Eur J Pub Health 20:47-51

8. Skrivarhaug T, Bangstad H-J, Stene LC et al (2006) Long-term mortality in a nationwide cohort of childhood-onset type 1 diabetic patients in Norway. Diabetologia 49:298-305
9. Nishimura R, LaPorte RE, Dorman JS et al (2001) Mortality trends in type 1 diabetes. The Allegheny County (Pennsylvania) Registry 1965-1999. Diabetes Care 24:823-827

10. Lung TWC, Hayes AJ, Herman WH et al (2014) A meta-analysis of the relative risk of mortality for type 1 diabetes patients compared to the general population: exploring temporal changes in relative mortality. PLoS One 9, e113635

11. Asao K, Sarti C, Forsen T et al (2003) Long-term mortality in nationwide cohorts of childhood-onset type 1 diabetes in Japan and Finland. Diabetes Care 26:2037-2042

12. Livingstone SJ, Looker HC, Hothersall EJ et al (2012) Risk of cardiovascular disease and total mortality in adults with type 1 diabetes: Scottish registry linkage study. PLoS Med 9, e1001321

13. Harjutsalo V, Forsblom C, Groop P-H (2011) Time trends in mortality in patients with type 1 diabetes: nationwide population based cohort study. BMJ 343:d5364

14. Secrest AM, Becker DJ, Kelsey SF et al (2010) Cause-specific mortality trends in a large population-based cohort with longstanding childhood-onset type 1 diabetes. Diabetes 59:3216-3222

15. Jørgensen ME, Almdal TP, Carstensen B (2013) Time trends in mortality rates in type 1 diabetes from 2002 to 2011. Diabetologia 56:2401-2404

16. Harding JL, Shaw JE, Peeters A et al (2014) Mortality trends among people with type 1 and type 2 diabetes in Australia: 19972010. Diabetes Care 37:2579-2586

17. Livingstone SJ, Levin D, Looker HC et al (2015) Estimated life expectancy in a Scottish cohort with type 1 diabetes, 2008-2010. JAMA 313:37-44

18. Orchard TJ, Secrest AM, Miller RG, Costacou T (2010) In the absence of renal disease, 20 year mortality risk in type 1 diabetes is comparable to that of the general population: a report from the Pittsburgh Epidemiology of Diabetes Complications Study. Diabetologia 53:2312-2319

19. Orchard TJ, Costacou T, Kretowski A, Nesto RW (2006) Type 1 diabetes and coronary artery disease. Diabetes Care 29:2528-2538

20. Laing SP, Swerdlow AJ, Slater SD et al (2003) Mortality from heart disease in a cohort of 23,000 patients with insulin-treated diabetes. Diabetologia 46:760-765

21. Groop P-H, Thomas MC, Moran JL et al (2009) The presence and severity of chronic kidney disease predicts all-cause mortality in type 1 diabetes. Diabetes 58:1651-1658

22. Eliasson B, Gudbjörnsdottir S (2014) Diabetes care - improvement through measurement. Diabetes Res Clin Pract 106:S291-S294

23. Gudbjörnsdottir S, Cederholm J, Nilsson PM, Eliasson B (2003) The National Diabetes Register in Sweden: an implementation of the St. Vincent Declaration for Quality Improvement in Diabetes Care. Diabetes Care 26:1270-1276

24. Lung TWC, Petrie D, Herman WH et al (2014) Severe hypoglycemia and mortality after cardiovascular events for type 1 diabetic patients in Sweden. Diabetes Care 37:2974-2981

25. Ludvigsson JF, Andersson E, Ekbom A et al (2011) External review and validation of the Swedish national inpatient register. BMC Public Health 11:450

26. Wettermark B, Hammar N, MichaelFored C et al (2007) The new Swedish Prescribed Drug Register-opportunities for pharmacoepidemiological research and experience from the first six months. Pharmacoepidemiol Drug Saf 16:726-735

27. Swedish National Diabetes Register (2014) Annual report 2013. NDR, Gothenburg

28. Hoelzel W, Weykamp C, Jeppsson J-O et al (2004) IFCC reference system for measurement of hemoglobin A1c in human blood and the national standardization schemes in the United States, Japan, and Sweden: a method-comparison study. Clin Chem 50:166-174

29. Levey AS, Stevens LA, Schmid CH et al (2009) A new equation to estimate glomerular filtration rate. Ann Intern Med 150:604-612 
30. Johansson LA, Björkenstam C, Westerling R (2009) Unexplained differences between hospital and mortality data indicated mistakes in death certification: an investigation of 1,094 deaths in Sweden during 1995. J Clin Epidemiol 62:1202-1209

31. Eurostat (2014) Life tables - age specific mortality rates. http://ec. europa.eu/eurostat/statistics-explained/index.php/Mortality_and life expectancy_statistics. Accessed 21 Mar 2015

32. Chiang CL (1984) The life table and its applications. Krieger Publishing, Malabar

33. Andersen PK, Borch-Johnsen K, Deckert T et al (1985) A Cox regression model for the relative mortality and its application to diabetes mellitus survival data. Biometrics 41:921-932

34. Pohar M, Stare J (2006) Relative survival analysis in R. Comput Methods Prog Biomed 81:272-278

35. White IR, Royston P, Wood AM (2011) Multiple imputation using chained equations: issues and guidance for practice. Stat Med 30: 377-399

36. Björck L, Capewell S, Bennett K et al (2011) Increasing evidencebased treatments to reduce coronary heart disease mortality in Sweden: quantifying the potential gains. J Intern Med 269:452-467

37. Vestberg D, Rosengren A, Olsson M et al (2015) Decreased eGFR as a risk factor for heart failure in 13781 individuals with type 1 diabetes. J Diabetes Sci Technol 10:131-136

38. Nathan DM, Cleary PA, Backlund JY et al (2005) Intensive diabetes treatment and cardiovascular disease in patients with type 1 diabetes. N Engl J Med 353:2643

39. Janssen I, Katzmarzyk PT, Ross R (2005) Body mass index is inversely related to mortality in older people after adjustment for waist circumference. J Am Geriatr Soc 53:2112-2118

40. Rönnback M, Isomaa B, Fagerudd J et al (2006) Complex relationship between blood pressure and mortality in type 2 diabetic patients. a follow-up of the Botnia Study. Hypertension 47:168-173

41. Huxley RR, Peters SAE, Mishra GD, Woodward M (2015) Risk of all-cause mortality and vascular events in women versus men with type 1 diabetes: a systematic review and meta-analysis. Lancet Diabetes Endocrinol 3:198-206

42. Kjellsson G, Gerdtham U-G, Petrie D (2015) Lies, damned lies and health inequality measurements: understanding the value judgements. Epidemiology 26:673-680

43. Poole C, Shrier I, VanderWeele TJ (2015) Is the risk difference really a more heterogeneous measure? Epidemiology 26:714-718

44. Rawshani A, Landin-Olsson M, Svensson AM et al (2014) The incidence of diabetes among 0-34 year olds in Sweden: new data and better methods. Diabetologia 57:1375-1381

45. Eliasson B, Liakopoulos V, Franzén S et al (2015) Cardiovascular disease and mortality in patients with type 2 diabetes after bariatric surgery in Sweden: a nationwide, matched, observational cohort study. Lancet Diabetes Endocrinol 3:847-854

46. Morimoto A, Onda Y, Nishimura R et al (2013) Cause-specific mortality trends in a nationwide population-based cohort of childhood-onset type 1 diabetes in Japan during 35 years of follow-up: the DERI Mortality Study. Diabetologia 56:2171-2175

47. Onda Y, Nishimura R, Morimoto A et al (2015) Causes of death in patients with childhood-onset type 1 diabetes receiving dialysis in Japan: Diabetes Epidemiology Research International (DERI) Mortality Study. J Diabetes Complicat 29:903-907

48. Matsushima M, Tajima N, LaPorte RE et al (1995) Markedly increased renal disease mortality and incidence of renal replacement therapy among IDDM patients in Japan in contrast to Allegheny County, Pennsylvania, USA. Diabetologia 38:236-243

49. Svensson M, Nyström L, Schön S, Dahlquist G (2006) Age at onset of childhood-onset type 1 diabetes and the development of endstage renal disease. A nationwide population-based study. Diabetes Care 29:538-542

50. Lind M, Svensson A-M, Kosiborod M et al (2014) Glycemic control and excess mortality in type 1 diabetes. $\mathrm{N}$ Engl $\mathrm{J}$ Med 371: 1972-1982 